\title{
Enacting risk in independent technological innovation
}

\author{
Henrik Berglund \\ Department of Innovation Engineering and Management, \\ Chalmers University of Technology, S-41296 Göteborg, Sweden \\ Fax: +4631772 1917 E-mail: henber@mot.chalmers.se
}

\section{Tomas Hellström}

Department of Management, Politics and Philosophy, Copenhagen Business, School, DK-2200 Copenhagen, Denmark E-mail: the.lpf@cbs.dk

\begin{abstract}
The present study aims at investigating the role of risk in the activity of independent technological venturing. Altogether 12 deep-interviews were conducted with technological entrepreneurs, who had taken part in the inventive, developmental and the commercialisation phases of a technologybased innovation process. The interviews revealed a number of enactment approaches through which these innovators encountered and affected (dealt with or transformed) risk within the innovation process. Factors thus developed from the empirical material included: human capital, pace and priority, the world moves, activating social networks, risk learning, risk incrementalism, maintaining venture agility, and creating and sustaining autonomy. The paper presents a theoretical contextualisation as to the significance of these factors, and finally suggests a number of ways in which these may be interpreted for the benefit of innovation management.
\end{abstract}

Keywords: Independent innovation; innovation process; micro-level innovation; risk; enactment; technological entrepreneur; deep-interviews.

Reference to this paper should be made as follows: Berglund, H. and Hellström, T. (2002) 'Enacting risk in independent technological innovation', Int. J. Risk Assessment and Management, Vol. 3, Nos. 2/3/4, pp.205-221.

Biographical notes: Henrik Berglund holds a MSc in Industrial Engineering and Management from Chalmers University of Technology, Sweden and has worked as a research assistant at the Institute for Management of Innovation and Technology. Currently he is a $\mathrm{PhD}$ candidate at the Department of Innovation Engineering and Management at Chalmers. His dissertation work focuses on the dynamics of micro-level innovation and includes analyses of risk and risk-taking, innovators' conception of self, and creativity in technological innovation.

Tomas Hellström is Associate Professor in Innovation Engineering and Management at Chalmers University of Technology. He holds a PhD in Theory of Science from the University of Gothenburg, Sweden. Hellström's research focuses on the sociology of technological innovation and Knowledge Management, especially with respect to new venturing processes. He has worked extensively with Swedish industry, among others Ericsson, Telia and Volvo. He is currently a Visiting Professor at Copenhagen Business School. 


\section{Introduction}

The study of entrepreneurship as a driver of technological innovation has provided Innovation Studies with a clear foundation in an actor or micro perspective. This perspective, which draws on a Schumpeterian grounding of the innovation process in inventive micro processes, has increasingly been popularised in attempts to build innovation systems from the bottom-up, e.g. by stimulating entrepreneurial or independent technological innovation within the context of incubators [1]. Such experiments beg the question of a number of aspects that pertain to entrepreneurial technological innovation, not least with regard to the innovating individual's view on what it is to drive a venture. Consequently the need to understand the social as well as the cognitive ramifications of these activities increases, particularly with respect to how entrepreneurial innovation is undertaken vis-à-vis established business traditions and social norms. The issues of entrepreneurial risk taking and risk management seems especially pressing in this regard; because of the inherent role of psychological waging and future advancements that innovation implies. The present paper aims at elucidating the variety of ways in which risk may be enacted, created and managed, by independent (entrepreneurial) innovators during the development of their ventures. The aim of this paper is to contribute to finding principles that could aid in better understanding innovative institutional frameworks and socio-cognitive mechanisms, as well as to the social psychology of innovation through applying the concept of risk.

The literature has commonly portrayed the individual who engages in entrepreneurial activities as a risk-taker (e.g. [2]). It is, to be sure, almost impossible to perceive of an entrepreneurial venture which does not imply risk-taking, and this basic insight puts the concepts of risk at the heart of understanding entrepreneurial and innovative activities. The activity of being a risk-taker in this context however is far from clear. The issue of who is an entrepreneurial risk-taker implies something beyond a simple definition of the concepts of risk and innovation, for instance a contextual when, where, and on behalf of whom, towards what kind of goals etc., that risk is oriented when enacted in the context of innovation.

The concept of risk has been said to imply a calculus of probabilities and consequences of an unwanted event [3]. However observing the entrepreneurial innovator, it becomes clear that risk is also a matter of pursuing and valuing goals of different kinds, of personal commitment, and of a constant changing of the social and physical ramifications of existing risk. What this means for our initial question, and where our paper takes a detour from what has been written in the area so far, is that for this kind of activity, which is essentially about affecting outcomes and establishing goals, the stable calculus of probabilities and consequences of unwanted events has to be extended to include the social and cognitive enactment of risk within the innovation: that is the dual process of proactively creating risk, and opportunistically avoiding it. The concept of enactment, where the individual and social merge in mutual creation, negotiation and reconfiguration, makes it possible to understand entrepreneurial innovation not as a simple combination of individual goals, traits and cash, but as a meaningful social and communicative activity of waging and projecting desirable futures.

In order to explore the way in which risk was enacted as part of the independent innovation process, we conducted open-ended, deep interviews with 12 technological entrepreneurs from a variety of new businesses concerning their relation to innovation and risk. The present paper builds around this empirical study. In what follows we will 
first review some of the extant contributions to the area of risk and entrepreneurial, technological innovation and further deepen the analysis of what the concepts of risk and innovation may gain from being put together. After that will follow a description of the methodological approach utilised for the empirical study. Next we will present the results from the interviews. The paper will finally discuss the results in the light of prior theorising, and also offer some guidelines as to how the concepts of risk and innovation may be combined to offer a guide for the management of bottom-up innovation activities.

\section{Elements of the problem}

\subsection{The conceptual kinship between risk and innovation}

Independent or entrepreneurial technological innovation is always risky, and the relationship between risk and such innovation has traditionally been explored from a multitude of perspectives, e.g. individual risk propensity and entrepreneurial success $[4,5]$, entrepreneurial risk-taking and cognitive biases [6,7], risk and entrepreneurial decision making [8-10], profit and entrepreneurial risk [11], and risk reduction techniques in product development [12,13]. Innovating necessarily entails a number of more or less unavoidable risks such as the risk of losing key personnel [14], financial risks [12], technological risks [15], and ego risk [16]. The conceptual kinship between risk and innovation is quite clear; both are forward-looking, action-oriented concepts that are closely related to uncertainty and change. Risk is a factor in all innovative processes in so far as purposeful, goal-directed action is always directed towards an uncertain future with some possible reward and that it is based on a particular stake, e.g. opportunity costs or waged real capital. That is to say, in order to realise an innovative potential, risk-taking is an unavoidable necessity.

\subsection{Innovation and independent technological venture creation}

Independent technology ventures may have a profound effect on the development of new technologies as well as on technology-based industries (cf. [17]). The important role of independence from large, stifling structures becomes especially evident in early phases of the innovation cycle, where agility and freedom of the independent technology based firm may allow it to quickly exploit technological breakthroughs and adapt to new business opportunities [18-20]. It has been found that small high-technology oriented firms generally tend to accept types and amounts of risk that are seldom tolerated by larger companies [21].

Traditionally, two approaches to understanding technological innovation on the level of the firm have figured prominently, namely the individualistic and the structural perspectives [22]; the individualistic being of major influence in the entrepreneurship research tradition and the structural being more influential in the innovation studies tradition. Both are needed in order to understand the present problematique. The individualistic tradition in entrepreneurship theory has conventionally focused on identifying personality antecedents of innovation either by correlating innovativeness with independent factors such as sex, age and family background (e.g. [23,24]), or by identifying stable psychological characteristics of successful entrepreneurs [25]. These efforts however have had limited success (e.g. [26,25]). Already Schumpeter [18] 
rejected the notion of stable entrepreneurial traits, in arguing that individuals are entrepreneurs only when performing entrepreneurial tasks. Many authors still argue that the individual focus is essential for our understanding of entrepreneurial innovation (e.g. [27,28]), and there is now an increasing acceptance that psychology based personality models may contribute to our understanding of innovative behaviour within certain theoretical limits. Increasingly concepts such as cognitive heuristics [6,7], bounded rationality (cf. [29]), attribution theory and expectancy theory [27] are seen to hold explanatory capacity vis-à-vis the phenomenon of independent innovation.

The second mentioned explanatory model of organisational innovation is the structural approach, where innovation is seen mainly as the result of external factors and organisational characteristics. In this tradition factors such as firm size and age, market conditions and competitors are brought to bear on innovative performance (e.g. [19,30]). Individual entrepreneurial behaviour has also been explained using structural factors, such as for instance in X-Efficiency Theory where entrepreneurship is viewed as the creative but reactive response to inefficient use of firm resources [31]. There are problems with both the individualist and the structuralist perspectives on innovation in that they have both had difficulties producing theory with empirical scope [25,32]. Also, both tend to focus on identifying innovation determinants to the detriment of a better understanding of the processual, action-oriented qualities of innovation.

Many attempts have been made to understand the micro-level process of innovation beyond the individualist and structuralist perspectives, and some authors see a more problematising, or critical view of innovation and entrepreneurship as the only way forward. Slappendel [33] holds that the traditional individualistic and structural approaches to innovation/entrepreneurship are matters of relative emphasis rather than conceptual difference. Bygrave and Hofer [34] propose that entrepreneurship theory needs to break with the linear models of traditional economics and psychology altogether and instead build theory grounded on "solid foundations from the social sciences" $[34, p .13]$. Lowe [35] further emphasises the need to understand the fundamental social processes of innovation, suggesting that this could be achieved through close and qualitative investigation of actual innovation processes. Most micro-level research conducted to date has failed to examine the innovation process in any empirical detail, and mostly resulted in anecdotal evidence, thus leaving "substantial gaps in our knowledge [...] about the detailed workings of innovation within SMEs" [32, p.49]. Clearly there is a gap in our understanding of the social and cognitive components and workings of new innovative firms.

Attempts have also been made to theoretically comprehend the micro-processes of innovation. Slappendel [33] suggests an interactive model of the innovation process that focuses on the complex and paradoxical interrelationship between action and structure, and on the voluntary as well as deterministic aspects of social systems. In trying to explain how the innovation process moves toward a desired goal, Nightingale [36] suggests a cognitive learning perspective on innovation. This approach focuses on individuals' tacit knowledge and cognitive mechanisms of pattern recognition. Through innovating persons' tacit understandings of traditions, the innovation process moves from problems and situations that are initially nebulous, to more specific ones in an iterative manner. This perspective emphasises the interaction between different actors in the innovation process, especially in terms of how these actors conceive of and negotiate problems and opportunities. 


\subsection{Cognitive and social conceptions of risk}

Early modern societies conceived of risk as both good and bad. This view has gradually shifted and today risk is mostly associated with negative outcomes [37]. The role of risk qua social science concept has been developed in two main directions: an epistemologically realist perspective, found in disciplines such as economics and cognitive science, and a constructivist perspective, which incorporates social and contextual influences on risk [38].

Cognitive science tends to view risk as a fully operational concept, which can be reduced and described in terms of probabilities and consequences (e.g. [39]). This tradition sees risk as evaluated, assumed and converted into action on a purely individual level [40]. In the innovation and entrepreneurship literature, cognitive biases are often considered static qualities capable of explaining why certain individuals accept higher levels of risk and thereby are more likely to, for instance, start firms (cf. [6,7]). An alternative view on risk and cognition may be found in the tradition of cognitive constructivism, where knowledge about risks is seen as created in an amalgamation of external influences and active cognising by the individual [41]. The cognitive process may thus be conceived of as a form of learning, which gradually reconstructs the individual's cognitive understanding of risk based on experience [42] and on tacit background knowledge [36].

From a more collectivistic, or sociologically influenced perspective, risk may be interpreted as constituted by the context and social situation in which action is embedded. Individuals continuously make conscious and unconscious decisions about what is risky; interpreting, judging and affecting risk with respect to those specific social and cultural frameworks in which these risks receive their meaning [40]. In the same vein it has been argued that individuals purposefully enact and project their own risk views and opinions with regard to specific situations, power structures, and institutional mores [43]. Risk then becomes a concept whose content and meaning is continuously negotiated and reconstructed in a dialectical relationship between individuals and their surrounding world. In the spirit of these ideas, many authors have argued in favour of a more locally oriented take on structures, knowledges, elites and action as the primary sources of risk views and innovative behaviours $[43,44]$. As members of specific local social groups and networks, individuals draw on temporary relationships and situations in constructing their risk views. These risk views also change and adapt with new knowledge and experience [45]. From the perspective of this paper, it is therefore necessary to closely examine the local experience of risk and innovation in order to approach innovators' relations to risk in a meaningful way. As this process seems difficult to understand within the confines of static, behaviourist methodology we must try to comprehend of innovators' enactment of risk by examining their actions as social activities.

\section{Method}

\subsection{Participants}

The empirical material of this study is based on interviews with 12 entrepreneurial technology innovators. The selection of interviewees draws on a purposive sampling strategy. The participants were sampled from a population of entrepreneurial innovators, 
distributed across Sweden, who had been active in their technology-based ventures for at least one year, or until such time when the venture had started to stabilise. They had all taken a key role in driving the process of inventing, producing and marketing a technological innovation, either in the field of information technologies, biotech or advanced services.

\subsection{Procedure}

The interview data was collected through in-depth interviews, which took place in the companies of the participants. The interviews lasted for 1,5-2 hours, and on average three interviewers took part in each occasion. Questions concerned the venture and innovation in general, and gradually the issue of risk in relation to the venture/innovation was touched upon, both with regard to the person (innovator) as well as to the company. In this respect the interviews were semi- to non-structured, and the interpretations of the participants were allowed room to emerge. The interviewers took turn in documenting the interview questions and answers in detailed notes, which were later cross-checked. The notes were finally written up into interview protocols.

\subsection{Analysis}

The interview protocols were read by the interviewers in order to establish interpretative flexibility and common meaning, and the interpretation and subsequent validity of the general narrative, as well as of the specific quotations were agreed upon. The individual protocols were then re-read line by line and broken down into discrete parts, or meaning units, i.e. visible change of meaning could be discerned [46]. These units were then clustered into categories that were agreed to capture specific homogeneous qualities of what was said by the participants. The categories and their interrelationships were focused on in more detail and similar themes were clustered into factors and over-arching super-factors (see below).

\section{Results of the interviews}

In what follows we will outline the results of the interviews. From the material could be gleaned two general super-factors located on an ontological level, i.e. pertaining to what kind of process the utterance referred to: in this case whether there was a risk to the innovation per se, or whether a risk reducing strategy (what we have termed innovation risk affected) was the focus. Under these super-factors, we have located general conceptual factors, which in turn subsume a number of constitutive categories of risk and innovation. These may be schematically represented as in Table 1 .

\subsection{Innovation risk encountered}

The super-factor of innovation risk encountered refers to forces of risk acting upon the innovation process, which are perceived to be somewhat independent of the innovator. The innovator so to speak, encounters these risks rather than creates them him/herself. 
Table 1 Super-factors, factors and categories of risk and innovation

\begin{tabular}{|c|c|c|}
\hline Super-Factors & Factors & Categories \\
\hline \multirow{3}{*}{$\begin{array}{l}\text { Innovation risk } \\
\text { encountered }\end{array}$} & Human capital & $\begin{array}{l}\text { Human capital risk } \\
\text { Abundance of slack and lack of coordination }\end{array}$ \\
\hline & Pace and priority & $\begin{array}{l}\text { Missing the time slot } \\
\text { Lack of time to evaluate decisions } \\
\text { First mover risk }\end{array}$ \\
\hline & The world moves & $\begin{array}{l}\text { Force majeure } \\
\text { Perception of venture capitalists } \\
\text { Product competition } \\
\text { Market response }\end{array}$ \\
\hline \multirow{5}{*}{$\begin{array}{l}\text { Innovation risk } \\
\text { affected }\end{array}$} & $\begin{array}{l}\text { Activating social } \\
\text { networks }\end{array}$ & $\begin{array}{l}\text { Managing risks through partnerships } \\
\text { Matching partnerships to venture pace } \\
\text { Network activation }\end{array}$ \\
\hline & Risk learning & $\begin{array}{l}\text { Internalising routines } \\
\text { Affecting perceptions of risk }\end{array}$ \\
\hline & Risk incrementalism & $\begin{array}{l}\text { Risk administration } \\
\text { Venture incrementalism } \\
\text { Opportunistic adaptation }\end{array}$ \\
\hline & $\begin{array}{l}\text { Maintaining venture } \\
\text { agility }\end{array}$ & $\begin{array}{l}\text { The venture as a test-case } \\
\text { Opportunity scanning/market pull }\end{array}$ \\
\hline & $\begin{array}{l}\text { Creating and sustaining } \\
\text { autonomy }\end{array}$ & $\begin{array}{l}\text { External innovation audits } \\
\text { Technological prowess } \\
\text { Piggybacking } \\
\text { Creation of momentum }\end{array}$ \\
\hline
\end{tabular}

\subsubsection{Human capital}

This factor has to do with risks to the organisation's human capital, e.g. its intellectual and attitudinal assets. The interviews suggested two main categories for this particular risk, namely human capital risk, and abundance of slack and lack of coordination. The human capital risk is to do with the difficulties in attracting and keeping the right competence for the innovation. This is probably an even more delicate matter for the technological venture than for other kinds of venturing activities. One innovator reported that: "The biggest challenge is to get people in quickly and to develop a critical mass, which is to say about 50 people. That is how many are needed to cover those scientific disciplines the technology needs to be developed". Another interviewee stated that: "We need to find the company a key inventor to keep continuity in technological innovation". But this category also entails the risk involved in being dependent on specific competences. This is illustrated in the following quote: "The venture is critically dependent on two developers [...] they are tied to the company with generous stock options. They are also tied together by friendship". Abundance of slack and lack of coordination is a category relating to work organisation and attitudes, and it probably represents a typical risk for the new venture. Also here the interviews give clear references to the peculiarities of the technological innovation. One interviewee reported that: "Research intense groups like ours have so much drive on the individual level that central coordination isn't really in effect, because it doesn't seem to be needed. Yet the lack of coordination, the mixing of business and developer roles, risks leading to us 
getting it wrong in the end". One start-up that had undergone rapid global expansion reported similar problems, but on another level of resolution: "Our company is so distributed geographically and culturally, that we often supply the wrong information. It's because of lack of communication".

\subsubsection{Pace and priority}

One of the central risks in the entrepreneurial technological venture lies in the pace of development of the innovation, and how fast one moves into new markets (i.e. priority). Central to this is the risk of missing the time slot of the venture (given that it has already started). One of the interviewees captured this succinctly: "The major threat to the venture is that the up-scaling of the technology takes time. I think that the big ones are eventually going to adopt this technology and when they do I hope they choose us". Lack of time to evaluate decisions implies another impediment to the innovation. This one is particularly common, and may be illustrated with the following quote: "[...] the tempo and the quick decisions have consequences for how you act. You employ the wrong people, and you don't evaluate the alternatives well enough". A third category that falls within the pace factor is that of first mover risk. In connection with this type of risk, one respondent stated that: "[...] one particular risk lies in not reaching the specifications; that the technical task is overpowering. Nothing has been done in this field: we're doing everything for the first time". Yet another illustrative comment on the pace theme was that: "We don't get any real trust from the outside, because we're not in a competitive market. Being the only competitor we're not viewed as very serious".

\subsubsection{The world moves}

One of the most prominent factors in terms of risk is of course when the outside world changes in ways that cannot be completely controlled for. We have named one category within this factor force majeure, to denote unexpected events totally outside of the innovators control, as is for instance illustrated by the quote: "NN (firm) has a number of outside calamities affecting it every week. One of the worst was probably when Ericsson decided to cancel the product that NN's whole venture was built around. Our entire strategy depended on Ericsson's infrastructure for distribution". Another outside factor of importance is the perception of venture capitalists (VCs). This category may be exemplified by the following: "Before we can move by our own force we have to attract enough capital from the VCs. Our business is very sensitive to shifts and trends in VC focus and interests. The venture might be good, but the capital market is thin-skinned". Or: "In the mid-90s we tried to get capital for an e-business idea, but were denied because VCs thought it was too much of a consultancy thing. They wanted to see a physical product in order to invest". One of the more obvious categories under this heading was product competition, e.g.: "The hardware is not itself unique [...] what we can try to protect is the system side and the services. [...] Almost everything [the hardware product] is standard components, and will be old in six to eight months". The closely associated category market response also fell out as important under this heading. One innovator stated that: "We are focusing too narrowly on the technical solution. Even if we have a very rich offering, with about a hundred services, the public won't see this or appreciate it. Education becomes very important". And in another company: "A system like this will inevitably replace some of the technology that the 
buyer had previously developed in-house. The engineers responsible for these developments will probably resist such purchase".

\subsection{Innovation risk affected}

The super-factor innovation risk affected has to do with the process of imposing order on the innovation process, or making fundamental uncertainties of the process more manageable or understandable to the innovator. This group of factors thus comes closest to what in ordinary terms would be called the risk management processes of the innovator.

\subsubsection{Activating social networks}

This general factor has to do with spreading risk through the use of social networks, e.g. partnerships of various kinds. One such category is managing risks through partnerships. The category may be exemplified by the following quote: "In this field one can have almost as many partnerships as one likes. Many partnerships, for instance with consultants, spread the risks and cover up the holes in competence and in the market". A more specific category under this factor is the active matching of partnerships to venture pace. This is necessary since given the pace of the own innovation, a partnership can make or break a venture. An example is: "Given the time that was felt needed for the technology to mature, ordinary VCs were not approached, but rather more long term investors like NN and NN (firms); partners who could endure for a longer time without pay offs". Networks may also have to be activated for the purposes of continuously leveraging risk. This may well imply vision mongering or strategic positioning. Network activation is a category that tries to capture this, e.g.: "Academic researchers want to find and describe processes, and the biotech companies want to develop products. We take a very rewarding position in between". Or: "NN has activated several strategic actors by describing visions. Now we have to deliver".

\subsubsection{Risk learning}

This factor denotes the risk reducing practices implied in developing an understanding of the processes of innovation as well as a strong perception of one self as being an innovator. One category in this set of practices is that of internalising routines from previous activities. One innovator stated that: "Employment in a larger company like P increases the possibilities of succeeding [...] it gives the routines and process knowledge necessary for running your own company". Yet another category under this factor has to do with how the technology based innovator sees the professional background as supporting self-efficacy in the venture, e.g.: "The outlook I had with me from experimental physics was important here [...] to develop something towards a long-term goal in a complex environment. It's important to master your path, but not necessarily the totality of it all". Since risk is also residing in the minds of external actor, which in turn has implications for the venture, it becomes important to work with affecting perceptions of riskiness. One typical situation in this regard was expressed as follows: "It is a central concern to build trust vis-à-vis our technological platform. This has to do not only with technical development, but also with getting the right investors to join. Investors have a 
herd mentality. One also has to build trust with renowned customers. They have a herd mentality too".

\subsubsection{Risk incrementalism}

Risk may be managed by means of a set of practices that work with gradual adjustments of the venture to the outside world. One category within this orientation we have termed risk administration, to illustrate how the innovators develop means to continuously deal with the expected. An example of this may be gleaned from the following quote: "There are always risks in product development, and these are managed through technical contingency plans and administrative re-prioritisations. It's usually time and money that are the real consequences of these risks. Another, weaker expression of this is that: [...] it feels as if future risks are marginal. Like variations on themes that are already known".

Incrementalism may also be actively used as a risk-reducing device, by adjusting the increments of progress to a certain level. We have chosen to call this category venture incrementalism, and the following two statements may exemplify this: "The challenge is to identify those segments which work best initially. The first ones do not have to make us fly to the moon. [...] First it should work technically". And: "The technology has to be able to crawl before it can walk. It's OK to wait for robustness, because then there will be a better chance that heavy players want to come in and try out the concept". Another form of incrementalism is found in opportunistic adaptation where the future is seen as uncertain but manageable. This category may be exemplified in the following way: "We have entered those areas where it was the easiest to get in. Once we make it there we can move on. Our strategy is to search for the simplest; to find a clear road to the goal, with as few threats as possible". This type of opportunistic conception of the future may also be gleaned from the point of view of VCs, e.g.: "I began with the assumption that we would build our hardware etc. That was not a realistic plan, but we still got money from VCs, who probably knew the idea would be radically changed".

\subsubsection{Maintaining venture agility}

This factor depicts how the innovator reports dealing with risk through staying attentive to possibilities and maintaining a range of alternatives for future action. It resembles the previous factor in its willingness to change in accord with future demands, but with the important difference that future-orientations are not seen as reactive adaptations as much as the active pursuit of possible futures. An example of this may be found in the strategy of using the venture as a test case, i.e. to drive the venture as an experimental step towards a more comprehensive innovation. This may be exemplified in the following quote: "Three people wrote a business plan for the technology, and aimed at a business area which was fairly small, but easy to sell in. We knew then that this market was too small for the product, but it had good qualities as a testing ground". Opportunity scanning, or market pull strategies are about goal-oriented progress, constant scanning for opportunities, and willingness to change directions based on market impetuses. Two statements that well illustrate this category are: "Hardware and software have got a short best-before date. We have gained time, about six to eight months, vis-à-vis our competitors by having been the first to think in terms of the business, and then to generate the necessary technology". Or even more concretely: "The venture is our baby, not the technology. Risk management to us is therefore maintaining a clear business 
focus and to constantly seek out new products and services. We will not become rich from [product name]".

\subsubsection{Creating and managing autonomy}

The last, but possibly most interesting factor under the super-factor of sustaining innovation processes is that of creating and managing the autonomy of the venture. Several of the interviewed innovators found it useful to utilise different kinds of external innovation audits in order to assure innovative integrity of the venture. One way in which an interviewee achieved this is given in the following quote: "I tried to get my academic colleagues to shoot down the idea on several occasions, but it withstood their attempts. That way I figured the technological risk was accounted for". Another, more externally oriented version was that: "The most important thing is not to get the product out on the market in a certain space of time, but rather to get an external actor to validate the concept by showing an interest in that particular technology". Technological prowess is a version of the previous category, where the innovator uses the strength of the technology to achieve autonomy. One example of this was: "The idea is like a shotgun; it's so versatile that it can be adapted to new applications, if the initially chosen ones for some reason wouldn't work. These additional exits help minimising the risks". On the administrative/financial side we have found piggybacking to be the rule rather than the exception. Piggybacking is clearly a commonplace informal strategy for furthering the autonomy of the venture, e.g.: "Too little and too dedicated money is another risk. We took money budgeted by S (public utility) for machine purchases and used part of it for developing the innovation. [...] It's easier to obtain forgiveness than permission". The last category under this general factor relates to the creation of momentum for purposes of getting into and staying in the race as an autonomous player. One innovator addressed this phenomenon directly and stated that: "In a short period of time we have met numerous VC, recruited personnel, made 350 presentations and presented at eight tradefairs. This has kept the wheels spinning [...] one keeps up the momentum".

\section{Discussion}

The super-factors that emerged from the interviews could be said to divide the risk universe of the innovator into two different streams: one where risk is typically encountered as something fairly given, or outside of the innovator's control, and one where the innovator affects risk, exploits it, uses uncertainties to his/her benefit, or manages them in the traditional sense. As much as the two super-factors of encountered and affected innovation risk were given by the empirical material, and often outspokenly looked upon as distinct by innovators themselves (in the sense that some risks are manageable while others are not), we hold both to be weaved together on an empirical as well as an analytical level. The analytical stability of these super-factors may in fact be less than their empirical stability. Analytically we have been using the concept of enacting to encompass both processes of encountering and affecting particular risks. Enactment here refers to a process in which personal, social, and factual conditions merge in some sort of active creation of the external reality. Enacting risk then suggests a sense-making process in which individuals negotiate and create understanding of what are risks. As stated in the introduction of this paper, while the literature has commonly 
referred to the innovating entrepreneur as a risk-taker (e.g. [2]), the implications of enactment developed above thus actively undermines this notion, by reconstructing the possibility of taking risk as being synonymous with taking a cup of tea. The treatment of the various factors below should be understood as an attempt at elucidating the transcendent components of risk and innovation.

The category of human capital comprises risks that relate to the individuals who are employed in, and affiliated with the venture. These risks may be similar to those found in most firms, but due to the turbulent and demanding context in which most hightechnology start-up ventures are situated, the dependence on specific individuals and their relations may be extreme. At the same time as there is need for specific competences (e.g. academically grounded and market oriented), such competences must, apart from being present, also work together and grow with the firm. In this situation it is imperative to find the balance between the dynamism and freedom needed to successfully manage people and develop the business idea, and the stability required for the firm to survive. Thus human capital risks may be seen as being core to the innovation-efficiency dilemma often taken to be a question of innovation-design [47].

The pace and priority category is at the very heart of high-tech innovation. In a situation ridden with novelty, uncertainty, and lack of time there is always going to be pressure and a sense of not knowing for certain when and how to develop the venture. Pace and priority are certainly factors that the innovator encounters in the proper sense of the word, however, the true significance of this category is gleaned in the context of affecting better positions and comprehending issues of strategic positioning (more on this below).

The world moves may be taken to symbolise the unruliness and relentlessness of the surrounding context of the innovation. However well planned and executed there is always room for non-negotiable risks in the venture development process. These can spring from natural occurrences, e.g. fluctuations due to the unpredictable nature of the human spirit, in short, factors whose nature are out of any convenient form of control, and whose emergence are difficult to predict. The above mentioned innovation risks we have chosen to refer to as encountered as they are often more or less inescapable (which is not to say they lack interpretative flexibility). In order to comprehend these risks and develop the venture in a meaningful way the innovator has to deal with them in a constructive way. A number of approaches to how this was achieved fell out during the interviews.

Under the super-factor of innovation risk affected we find a number of factors which draw on the innovator's capacities to act and affect change vis-à-vis the venture. Activating social networks is particularly indicative of this. The new independent venture is an entity whose boundaries are seldom very clear. By consciously opening up the borders of the firm, drawing on the resources available from both professional and personal networks, the firm is shown to be able to act as if it were a larger organisation equipped with more knowledge and resources. In the light of this, such activities can be seen as strategic, dynamic positioning within an actor-network. In drawing on a number of actors such as financers, consultants, and potential customers, an entrepreneur is able to share risks both directly and indirectly. Advantageous positioning and use of available networks is an important strategy used by innovators to both avoid risks and create opportunities. By activating different parts of the available networks at different times it seems possible to adapt its benefits to current needs. By employing this strategy the venture is also able to navigate in the world with a form of buffering layer surrounding it. 
This buffer contains both reactive shock-absorbing types of capacity as well as more actively oriented potential. In this sense we expand the insights of Giddens [48] and Slappendel's [33] interactive take on innovation towards a network conception of how innovators enact the differences between action and larger structure in their ventures.

From the perspective of knowledge generation, risk learning represents a similar factor in this regard in that experiences from large corporations, academia, and the venture itself seems to help create confidence and understanding of the innovation process as goal-driven activity, as well as of one's own place within this process. This connects strongly to the insights of Nightingale [36] concerning the innovation process as a learning and recognising activity. However, rather than Nightingale's emphasis on the goal as constitutive, our findings put the discovery of an underlying logic in focus, and consequently recognise the possibility to learn from and master uncertainty as goals proper.

Risk incrementalism depicts how, by carefully developing the venture, the innovator achieves a form of control over the often-uncertain environment. This enactment should not be confused with simply playing it safe, or with the science of muddling through which can often be a very rational approach in bureaucratic settings [49]. Opposite to muddling through policy making, the motives behind an incrementalist innovation strategy often seem to be very ambitious, and careful development of the venture (e.g. limited market introduction) is viewed by many actors as part of the product development process; incremental adjustments of the venture is part of a testing phase which aims at developing a more successful product. In this respect, the venture development is dependent on how certain the future is and on what kind of mastery the firm believes it can exert on this future.

One way of dealing with the risks faced by independent technology ventures is through maintaining a high level of energy in the innovation process, thereby making it alert and agile. Under the heading of maintaining venture agility we see how the innovator, instead of seeking to reduce risks along a chosen path, continuously explores different opportunities and entertains a number of alternative routes of action. Through active management and exploration of a range of possible ways forward, the innovation process is kept on its toes and is given leverage toward the future. This process is related to the locally oriented and adaptive view of risk, innovation and the future as proposed by e.g. Wynne [43], Hage and Dewar [44], and Macgill [45]. In this view, the innovator is aware that the existing evolution of the venture is but one of many ways in which the process could be developed, and since the venture is able to draw on an array of possible alternative futures it is always ready to move swiftly in one direction or the other either by internally generated preferences, or by dint of external demands.

From the point of view of affecting innovation risk the factor creating and sustaining autonomy seems to address a couple of unresolved dilemmas of innovation. Previous studies for instance show that too much or too limited freedom tends to inhibit innovativity (e.g. [47]). Though independent technology ventures are formally rather independent, they are usually under constant pressure by numerous stakeholders such as VCs, owners or partners and customers. The present study showed that in order to deal with the risk of becoming too restrained by these external forces, some innovators tend to actively seek out a sphere or path, in which they are allowed to develop the venture according to their own desires. This reliance on the self and resistance to outside pressures may be viewed as a manifestation of a form of entrepreneurial reflexivity 
$[48,50]$ in which the external world, chaotic as it may appear, is something definite and given to which the innovator relates and sometimes shields him/herself from. In some instances of our empirical investigation such action was seen as a logical preventive measure, e.g. by allowing the venture to be reliant on the innovator or the venture team the risks of uninformed influence is reduced. On other occasions the will to autonomy was more of an existential factor pertaining to the innovation team's (or the innovator's) personal identification with the venture.

\section{Conclusions}

As may be gleaned from the above, our treatment of risk in the innovation process is not so much preoccupied with direct, or so-called objective risks, as with innovators' sensemaking conceptualisations of risk as part of the venture. The closest we come to objective risks would be in the first of the super-factors, i.e. innovation risk encountered, albeit even here what is pronounced in the interviews and reflected in the categories is on a higher level of abstraction than objective risk is normally conceived [3]. In this respect the categories in our analysis oftentimes act as mediators and filters of what could be called more direct risks. The interviews surfaced a number of risks that came more close to this hands-on category, e.g. financial and technical aspect of innovation. However, important as these may be for business plans etc., they do not speak to the basic socialcognitive processes of innovation, and are therefore of limited value within the ambit of the present treatment. Rather, these direct risks constitute a pervasive but secondary influence that indirectly manifests itself in categories such as perception of venture capitalists, force majeure, market response, and first mover risk. What is interesting from such a perspective is how the inevitabilities, or mundanity, of technological and financial risks are encountered and affected (i.e. enacted) in the everyday activities of technological innovators, through the applications of categories such as those above.

One way of using the factors and categories presented is as an analytical tool in the evaluation of more direct risks. If for example one were to evaluate the technological risks facing a given venture, a systematic discussion of these risks based on the factors and categories described could produce a considerably broader understanding of what the relevant aspects of risk in entrepreneurial innovation are and what corresponding foci for risk analysis should be. The factors ought thus not be seen as descriptors of different risks, but as generic and intermediary focus points which hold explanatory capacity regarding specific simple risks as well as the entrepreneurial innovation situation writ large.

Many authors have suggested that some portion of naivety on behalf of managers and entrepreneurs is positive (e.g. [51]), which is to suggest that stubbornness and overconfidence are sometimes preferable to over-careful reflection. However, our study also lends credence to the claim that entrepreneurial strategies may be studied and acquired [52], which, self-reflexively, suggests that findings such as the above could be useful for innovators in a quite direct way, e.g. in a learning context. In terms of stimulating a bottom-up innovation initiative, e.g. incubator activities, different mechanisms like education or counselling/advice could be used to support processes that have been shown to work.

As shown in the above, risk and innovation are intimately intertwined; both on an analytical as well as on an empirical level. Risk is always an issue in entrepreneurial 
innovation, both in terms of direct risks to the venture, and on a more subtle and indirect account where risk spurs innovative capacities and allows the entrepreneur to exploit a variety of options. Instead of seeking quantitative relationships between e.g. exogenous factors and growth or generally describing the micro level situation with respect to abilities or traits, there is a clear need to conduct more focused inquiries on the social micro-dynamics of innovation qua process. Through bringing the concepts of risk and innovation together in an exploration of how risks are enacted by high-technology entrepreneurs, we have been able to able to draw tentative conclusions about how different risks are encountered and affected on the micro-level of innovation. Such a mapping of risk and risk practices may begin to fill an important gap in existing knowledge about what guides and motivates entrepreneurial innovation.

\section{References}

1 Etzkowitz, H., Schuler, E. and Gulbrandsen, M. (2000) 'The evolution of the entrepreneurial university' in M. Jacob and T. Hellström (Eds.) The Future of Knowledge Production in the Academy, Buckingham: Open University Press, pp.40-60.

2 Begley, T.M. and Boyd, D.P. (1987) 'Psychological characteristics associated with performance in entrepreneurial firms and smaller businesses', Journal of Business Venturing, Vol. 2, pp.79-93.

3 Starr, C. (1969) 'Social benefits versus technological risks', Science, Vol. 165, pp.1232-1238.

4 Brockhaus, R.H. (1980) 'Risk taking propensity of entrepreneurs', Academy of Management Journal, Vol. 23, No.3, pp.509-520.

5 Stewart, W.H., Jr., Watson, W.E., Carland, J.C. and Carland, J.W. (1999) 'A proclivity for entrepreneurship: A comparison of entrepreneurs, small business owners and corporate managers', Journal of Business Venturing, Vol. 14, No.2, pp.189-214.

6 Busenitz, L.W. (1999) 'Entrepreneurial risk and strategic decision making: it's a matter of perspective', The Journal of Applied Behavioural Science, Vol. 35, No.3, pp.325-340.

7 Simon, M., Houghton, S.M. and Aquino, K. (1999) 'Cognitive biases, risk perception and venture performance: how individuals decide to start companies', Journal of Business Venturing, Vol. 15, pp.113-134.

8 Sitkin, S.B. and Pablo, A.L. (1992) 'Reconceptualizing the determinants of risk behaviour', The Academy of Management Review, Vol. 17, No.1, pp.9-39.

9 Sitkin, S.B. and Weingart, L.R. (1995) 'Determinants of risky decision-making behaviour: a test of the mediating role of risk perceptions and propensity', Academy of Management Journal, Vol. 38, No.6, pp.1573-1592.

10 Forlani, D. and Mullins, J.W. (2000) 'Perceived risks and choices in entrepreneurs' new venture decisions', Journal of Business Venturing, Vol. 15, No.4, pp.305-322.

11 Knight, F.H. (1971) Risk, Uncertainty and Profit, Chicago: University of Chicago Press.

12 Souder, W.E. and Bethay, D. (1993) 'The risk pyramid for new product development: An application to complex aerospace hardware', The Journal of Product Innovation Management, Vol. 10, No.3, pp.181-195.

13 Halman, J.I.M., Keizer, J.A. and Song, X.M. (1999) 'Perceived risks in product innovation projects: development of a risk skeleton', Working Paper 99.11, Eindhoven Center for Innovation Studies, Eindhoven University of Technology: Eindhoven.

14 Bevan, S. (1997) 'Quit stalling', People Management, Vol. 3, No.23, pp.32-35.

15 Hartmann, G.C. and Lakatos, A.L. (1998) 'Assessing technology risk - a case study', Research Technology Management, Vol. 41, No.2, pp.32-39. 
16 Bhidé, A. (2000) The Origin and Evolution of New Businesses, New York: Oxford University Press.

17 Fontes, M. (1997) 'Creation and development of new technology based firms in peripheral economies' in Klofsten, M. and Jones-Evans, D. (Eds.) Technology, Innovation and Enterprise - The European Experience, London: Macmillan, pp.107-147.

18 Schumpeter, J.A. (1934) The Theory of Economic Development, New York: Oxford University Press.

19 Abernathy, W. and Utterback, J. (1987) 'Patterns of industrial innovation', Technology Review, Vol. 80, No.7, pp.78-89.

20 Wennekers, S. and Thurik, R. (1999) 'Linking entrepreneurship and economic growth', Small Business Economics, Vol. 13, No.1, pp.27-55.

21 Guile, B., Kressel, H., Berlekamp, E.R., Bowen, H.K., Davis, R.M., Engelberger, J.F., Laubach, G.D., Schmitt, R.W. and Turing, G.L. (1995) Risk and Innovation: The Role and Importance of Small, High-Tech Companies in the U.S. Economy, Washington, D.C.: The National Academy Press.

22 Wolfe, R.A. (1994) 'Organizational innovation: review, critique and suggested research directions', The Journal Of Management Studies, Vol. 31, No.3, pp.405-431.

23 Scott, S.G. and Bruce, R.A. (1994) 'Determinants of innovative behaviour: a path model of innovation in the workplace', Academy of Management Journal, Vol. 37, No.3, pp.580-607.

24 Kolvereid, L. (1996) 'Prediction of employment status choice intentions', Entrepreneurship Theory and Practice, Vol. 21, No.1, pp.47-57.

25 Gartner, W.B. (1988) 'Who is an entrepreneur? Is the wrong question', American Journal of Small Business, Vol. 12, No.3, pp.11-32.

26 Hatten, T.S. (1997) Small Business: Entrepreneurship and Beyond, Upper Saddle River: Prentice-Hall.

27 Shaver, K.G. and Scott, L.R. (1991) 'Person, process, choice: the psychology of new venture creation', Entrepreneurship Theory and Practice, Vol. 16, No.2, pp.23-46.

28 Naffziger, D.W., Hornsby, J.S. and Kuratko, D.F. (1994) 'A proposed research model of entrepreneurial motivation', Entrepreneurship Theory and Practice, Vol. 18, No.3, pp.29-42.

29 Cooper, A., Folta, T. and Woo, C. (1995) 'Entrepreneurial information search', Journal of Business Venturing, Vol. 10, pp.107-120.

30 Porter, M. (1985) Competitive Advantage, New York: The Free Press.

31 Leibenstein, H. (1979) 'The General X-Efficiency Paradigm and the role of the entrepreneur' in Rizzio, M. J. (Ed.) Time, Uncertainty and Disequilibrium, Lexington, MA: D.C. Heath, pp.127-139.

32 Hoffman, K., Parejo, M., Bessant, J. and Perren, L. (1998) 'Small firms, R\&D, technology and innovation in the UK: A literature review', Technovation, Vol. 18, No.1, pp.39-55.

33 Slappendel, C. (1996) 'Perspectives on innovation in organizations', Organization Studies, Vol. 17, No.1, pp.107-130.

34 Bygrave, W.D. and Hofer, C.W. (1991) 'Theorizing about entrepreneurship', Entrepreneurship Theory and Practice, Vol. 16, No.2, pp.13-22.

35 Lowe, A. (1995) 'The basic social processes of entrepreneurial innovation', International Journal of Entrepreneurial Behaviour and Research, Vol. 1, No.2, pp.54-76.

36 Nightingale, P. (1998) 'A cognitive model of innovation', Research Policy, Vol. 27, No.7, pp.689-709.

37 Bernstein, P.L. (1996) Against the Gods: The Remarkable Story of Risk, New York: John Wiley \& Sons.

38 Lupton, D. (1999) Risk, London: Routledge.

39 Luce, R.D. and Weber, E.U. (1986) 'An axiomatic theory of conjoint, expected risk', Journal of Mathematical Psychology, Vol. 30, pp.188-205. 
40 Douglas, M. (1994) Risk and Blame: Essays in Cultural Theory, New York: Routledge.

41 Doolittle, P.E. and Camp, W.G. (1999) 'Constructivism: the career and technical education perspective', Journal of Vocational Education Research, Vol. 16, No.1, pp.23-46.

42 Mayer, R.E. (1996) 'Learners as information processors: legacies and limitations of educational psychology's second metaphor', Educational Psychologist, Vol. 31, No.3/4, pp.151-161.

43 Wynne, B. (1996) 'May the sheep safely graze? A reflexive view on the lay-expert divide' in S. Lash, B. Szerszynski and B. Wynne (Eds.) Risk, Environment and Modernity, London: Sage, pp.44-83.

44 Hage, J. and Dewar, R. (1973) 'Elite values versus organizational structure in predicting innovation', Administrative Science Quarterly, Vol. 18, pp.279-290.

45 Macgill, S. (1989) 'Risk perception and the public: insights from research around Sellafield' in J. Brown (Ed.) Environmental Threats: Perception, Analysis and Management, London: Belhaven Press,

46 Giorgi, A. (1985) Phenomenology and Psychological Research, Pittsburgh: Duquesne University Press.

47 Clark, P. and Staunton, N. (1994) Innovation in Technology and Organization, London: Routledge.

48 Giddens, A. (1991) Modernity and Self Identity: Self and Society in the Late Modern Age, Oxford: Polity Press.

49 Lindblom, C. (1959) 'The science of 'muddling through', Public Administration Review, Vol. 19, pp.79-88.

50 Holland, R. (1999) 'Reflexivity', Human Relations, Vol. 32, No.4, pp.463-484.

51 March, J.G. and Shapira, Z. (1987) 'Managerial perspectives on risk and risk-taking', Management Science, Vol. 33, No. 11, pp.1404-1418.

52 Mitchell, R.K. (1997) 'Oral history and expert scripts: demystifying the entrepreneurial experience', International Journal of Entrepreneurial Behaviour and Research, Vol. 3, No.2, pp.122-139. 